\title{
Current educational status of pediatric rheumatology in Europe: the survey results E Demirkaya*1, S Özen ${ }^{1}$, T Saurenmann² and W Kuis ${ }^{3}$
}

\author{
Address: ${ }^{1}$ Hacettepe University, School of Medicine, Ankara, Turkey, ${ }^{2}$ Zurich University Children's Hospital, Zürich, Switzerland and ${ }^{3}$ Department \\ of Pediatric Immunology and Rheumatology, Utrecht, Netherlands \\ * Corresponding author
}

\author{
from 15th Paediatric Rheumatology European Society (PreS) Congress \\ London, UK. 14-17 September 2008 \\ Published: 15 September 2008 \\ Pediatric Rheumatology 2008, 6(SuppI I):PI54 doi:I0.II86/I546-0096-6-SI-PI54
}

This abstract is available from: http://www.ped-rheum.com/content/6/SI/PI54

(C) 2008 Demirkaya et al; licensee BioMed Central Ltd.

\begin{abstract}
Aim
To understand the status of education and problems the pediatric rheumatology practice in Europe, through a survey.
\end{abstract}

\section{Methods}

A 26-item questionnaire was conducted during the 14th Congress of the Pediatric Rheumatology European Society in Istanbul, 2007. Physicians who were practicing or studying within the field of pediatric rheumatology for at least one year were included in the survey.

\section{Results}

One hundred twenty eight physicians, 79 pediatric rheumatologists (five pediatric immunologists, 10 pediatric nephrologists), 34 pediatric rheumatology fellows and 15 adult rheumatologists completed the survey. The physicians were from: Europe 95 (81.9\%), South America 12 (10.4\%), Middle East 5 (4.3\%), Asia 2 (1.7\%), Africa 2 $(1.7 \%)$. The duration of training for pediatric rheumatology ranged between $1-5$ years (mean: $3.12 \pm 1.11$ ). Sixty physicians $(47.2 \%)$ evaluated their education as unsatisfactory and among those, 48 physicians (50.5\%) were from Europe. Subjects reported that they were capable of doing; intraarticular injections (83.3\%); soft tissue injections (47.6\%); evaluation of radiographs (67.5\%); whereas competence in the evaluation of computed tomography/magnetic resonance imaging (30.5\%); and musculoskeletal sonography $(16.7 \%)$ were much less.
Pediatric rheumatology has established a significant position in pediatrics. However, being a relatively new field in the realm of pediatrics, pediatric rheumatology education at the European level needs to be further discussed, revised and uniformed. 